\title{
Diagnosis of Papillon-Lefèvre syndrome: review of the literature and a case report
}

\author{
Zygmunt Adamski ${ }^{1}$, Dorota Burchardt², Tamara Pawlaczyk-Kamieńska², Maria Borysewicz-Lewicka², \\ Marzena Wyganowska-Świątkowska ${ }^{3}$
}

'Department of Dermatology, Poznan University of Medical Sciences, Poznan, Poland 2Department of Paediatric Dentistry, Poznan University of Medical Sciences, Poznan, Poland

${ }^{3}$ Department of Oral Surgery and Periodontology, Poznan University of Medical Sciences, Poznan, Poland

Adv Dermatol Allergol 2020; XXXVII (5): 671-676 DOI: https://doi.org/10.5114/ada.2020.100480

\begin{abstract}
Papillon-Lefëvre syndrome (PLS), classified as ectodermal dysplasia, is an autosomal recessive condition related to the cathepsin C (CTSC) gene mutation. The first clinical symptoms, occurring most commonly between the ages of 1 and 4, are palmoplantar hyperkeratosis and also periodontitis resulting in the loss of most or all teeth in the same sequence in which they erupted. Most often the redness of palms and soles precede the occurrence of keratoderma. Moreover, excessive sweating, moderate mental retardation, the tendency to purulent skin and internal organs infection may occur. Lack of cathepsin seems to have a crucial role in the intensity of symptoms. In most of the patients, there can be observed impairment of phagocytosis and chemotaxis of neutrophils, granulocytes, leukocytes and cytotoxic lesion of fibroblasts and macrophages. Also, functional impairment of lymphocytes, neutrophils, and monocytes is observed. The study, using flow cytometry, showed a decreased percentage of T cells CD8+ and increased CD4:CD8 ratio.
\end{abstract}

Key words: Papillon-Lefëvre syndrome, periodontitis, flow cytometry, lymphocytes.

\section{Introduction}

Papillon-Lefëvre syndrome (PLS) was first described in 1924 as a condition characterized clinically by palmoplantar hyperkeratosis and inflammatory destruction of periodontal tissues which results in premature primary and permanent teeth loss [1]. This autosomal recessive disorder, classified as ectodermal dysplasia, is caused by a mutation in the cathepsin C (CTSC) gene [2-4], which is mapped on the long arm of chromosome 11 (11q14-q21). This gene encodes the lysosomal protease cathepsin C, found in neutrophils, lymphocytes and epithelial cells [4]. About 250 cases of this disease have been reported worldwide [5], mainly in the Caucasians in Saudi Arabia [6]. The prevalence of PLS is estimated to be about 1 case per 4 million $[7,8]$. It occurs evenly in both sexes $[9,10]$ and in approximately $40 \%$ of cases, a familial occurrence is observed [9], where parental affinity increases the incidence by $33 \%$ [6].

The first clinical symptoms usually occur between the ages of 1 and 4 as hyperkeratosis of palms and soles and as periodontitis, often leading to the loss of most or all the teeth, in the same sequence in which they erupted $[6,7]$. The cutaneous lesions in the form of erythema of the palms and soles most often precede keratoderma. Later, the changes spread onto the dorsal surfaces, the Achilles tendon region and the skin of the knees and elbows where they manifest as psoriatic lesions [7, 11]. The disease is often accompanied by excessive sweating (hyperhidrosis) especially of the hands and feet, moderate mental retardation, the tendency to recurrent pyogenic infections of the skin (furuncles, gangrenous pyoderma) and abscesses of the internal organs, such as kidney [12] and liver [13, 14], most often caused by Staphylococcus aureus and Escherichia coli [10]. Intracranial calcifications are also observed, particularly around the cerebellar tentorium, falx cerebri and the choroid plexus of the lateral ventricle [9] described for the first time by Corson [15]. Twenty-five percent of patients have an increased susceptibility to infections [6]. It is also conducive to more frequent respiratory $[9,16]$ and urinary tract infections [17]. Among the less common symptoms associated with PLS, skin squamous cell carcinoma (SCC) [18], malignant

Address for correspondence: Tamara Pawlaczyk-Kamieńska DDS, PhD, Department of Paediatric Dentistry, Poznan University of Medical Sciences, 70 Bukowska St, 60-812 Poznan, Poland, e-mail: tpawlaczyk@ump.edu.pl Received: 1.11.2018, accepted: 6.03.2019. 
melanoma [19] and albinism [20] have been reported. Occasionally, there can be observed excessive body hair, xeroderma pigmentosa, arachnodactyly and deformation of the distal phalanges, nail dysplasia, retarded skeletal development and osteoporosis, pericarditis, psychonervous disorders such as depression, aggressiveness, and concentration disorders $[5,21]$.

\section{Diagnostics}

Despite so many symptoms and signs, the diagnosis of PLS is not an easy one. Diagnosis is based on clinical signs, and confirmed by genetic testing. Among monogenic syndromes which are accompanied by periodontitis, Papillon-Lefëvre syndrome is relatively unique due to periodontal inflammation being dominant in the clinical diagnosis, apart from palmoplantar hyperkeratosis [21]. It is sometimes difficult to make a correct diagnosis as there is no cutaneous symptoms or atypical course of periodontitis [22]. There may also be short-lasting manifestations presented shortly after birth only [23]. The process concerns primary and permanent dentition and the loss of primary teeth starts already at the time of their eruption, despite no root resorption [21].

Periodontitis does not respond to standard anti-inflammatory treatment and is manifested by the alveolar bone destruction and deep periodontal pockets [6, 2426]. Sometimes, periodontal abscesses, halitosis, swelling of the gums, pain on chewing and difficulty in taking food are observed [27]. Also, histopathological changes are non-specific, among which hyperkeratosis, parakeratosis, acanthosis [9] and neutrophils infiltration of superficial epithelial layers are most frequently observed [28]. In the sub-epithelial tissue, degenerative changes in plasma cells are noted, resulting from the inhibition of immunoglobulin synthesis. Similar changes are observed in fibroblasts and cementoblasts. Teeth roots are covered with a thin layer of acellular cementum [29]. A change in the permeability of the attachment epithelium and the gingival sulcus epithelium is observed, which promotes the spread of inflammation. This is accompanied by a reduced lymphocyte reaction to the presence of pathogens $[11,30]$. The balance between periopathogenes and the host's immune response is disturbed, which results in periodontitis.

The studies showed that the bacterial flora in PLS patients is the same as the flora presented in the patients with chronic periodontitis (CHP), such as spirochetes, Epstein-Barr and cytomegaloviruses (CMV) [27, 31, 32]. Also in PLS patients, Aggregatibacter actinomycetemcomitans ( $\mathrm{Aa}$ ) [31], Capnocytophaga gingivalis, Eikenella corrodens, black-pigmented Bacteroides and Fusobacterium $[9,32]$ were found in the gingival pockets. Microbiological examinations of 12 PLS patients with severe gingivitis, intense gingival bleeding, bone loss and deep periodontal pockets $(>6 \mathrm{~mm})$ showed in all of them the presence of Prevotella intermedia, Fusobacterium nucleatum, Peptostreptococcus micros, and Streptococcus intermedius. In 11 of them Treponema denticola, Bacteroides forsythus (Bf), Prevotella nigrescens, Eikenella corrodens, Selenomonas noxia, Campylobacter rectus, in 9 individuals Porphyromonas gingivalis $(\mathrm{Pg})$, and $\mathrm{Aa}$ in 8 subjects was found. The level of these bacteria was not particularly high. In areas of active inflammation $B f$ and $P g$ titre were isolated, both at a high level [27]. But it is believed that a severe course of PLS is associated with a specific host response rather than with any special bacterial flora similar to CHP [27].

Page and Schroeder [33] hypothesized that periodontal tissue damage might be due to an impaired function of neutrophils and monocytes as well as of the complement system. The majority of patients with PLS suffer from impaired phagocytosis and neutrophil chemotaxis as well as cytotoxic damage to fibroblasts and macrophages producing inflammatory mediators [14]. Haneke [9] noticed an increase in antibody titres against $A a$ and a reduced lymphocyte response to polyhydroxyalkanoates (PHA) or myogens produced by bacteria. However, Firatli et al. [34] observed impaired peripheral leukocyte chemotaxis and an increased expression of CD11b receptors, which was confirmed by functional tests. Subsequent authors reported damage to the function of lymphocytes [35] as well as of neutrophils and monocytes $[36,37]$. Polymorphonuclear granulocytes (PMNs) produce more proinflammatory cytokines, which compensates for their reduced ability to neutralize leukotoxins and elimination of $\mathrm{Aa}$ [38]. In the studies, an increased production of IL-8, IL-6, IL-1 $1 \beta$, IP-10 interleukins, and interferon $\gamma($ IFN- $\gamma)$ was observed [39].

Cathepsin C, a protein encoded by the CTSC gene, is the central coordinator for activation of many proteins of the immune system, including neutrophil serine proteases (NSP) [40]. Inactivation of NSP has many effects causing dysregulation of the body's response to bacterial infections [35]. Cathepsin is a protease found in neutrophils, lymphocytes, and keratinocytes. Mutation in the CTSC gene results in an almost complete loss of the enzyme function. More than 40 mutations of the CTSC gene have been described. Studies have shown that preserving enzymatic activity in $13 \%$ prevents the clinical manifestation, whereas the mechanism of the effect of cathepsin deficiency on periodontal disease is still unknown. Moreover, the mutation of the CTSC gene was also detected in two other conditions: Haim-Munk Syndrome and isolated form of prepubertal aggressive periodontitis (PAP) [22, 40-42]. However, these mutations do not differ from those observed in the PLS, and not all the cases of prepubertal periodontitis are accompanied by mutations of the CTSC [35]. Hewitt et al. [41] confirmed these findings and suggested that isolated PAP is not a genetically heterogeneous disorder, and only the PAP subgroup that exists with complete CTSC inactivity 
is a phenotypic variant of PLS. On the other hand, Tonetti and Mombelli [43], described a case of generally healthy patients with symptoms of PAP who, however, have increased susceptibility to infection. CTSC mutations in these patients confirmed the hypothesis that this subgroup of patients might be a phenotypic variant of PLS. It seems that prepubertal periodontitis is heterogeneous. The same group of researchers that associated the occurrence of PLS with a gene encoding a lysosomal protease, cathepsin C on chromosome 11, performed the first study confirming the autosomal recessive form of prepubertal periodontitis [40].

There is no clinical manifestation in the heterozygous patient for the cathepsin C gene. There was not found the relationship between CTSC mutation and other forms of periodontal disease. A two-allele CTSC mutation always results in complete loss of the enzyme function [39]. It has been shown that the decreased CTSC activity contributes to the abolition of activity and stabilization of the protease derived from polymorphonuclear (PMN) leukocyte. These proteases may play a key role to regulate and initiate immunological processes against microbes. Current studies which analyse the pathogenic role of CTSC deficiency in the development of periodontal disease have shown a decrease in the ability of PMNs to neutralize leukotoxin and to eliminate $A a$. Other studies indicate the significance of CTSC in the functioning of natural killers (NK) to control infection and confirm cytotoxicity towards NK in periodontitis in the course of PLS. A high expression of the cathepsin C enzyme is evident in polymorphonuclear leukocytes, macrophages, and their precursors, also in the epidermis affected by hyperkeratosis, and even on the alveolar ridge gum. Apart from genetic testing, confirming the IgG antibodies against Aa (ELISA) or anaerobic culture is of significance in the PLS diagnosis. The following factors are also of diagnostic importance: a significantly reduced level of coenzyme Q,

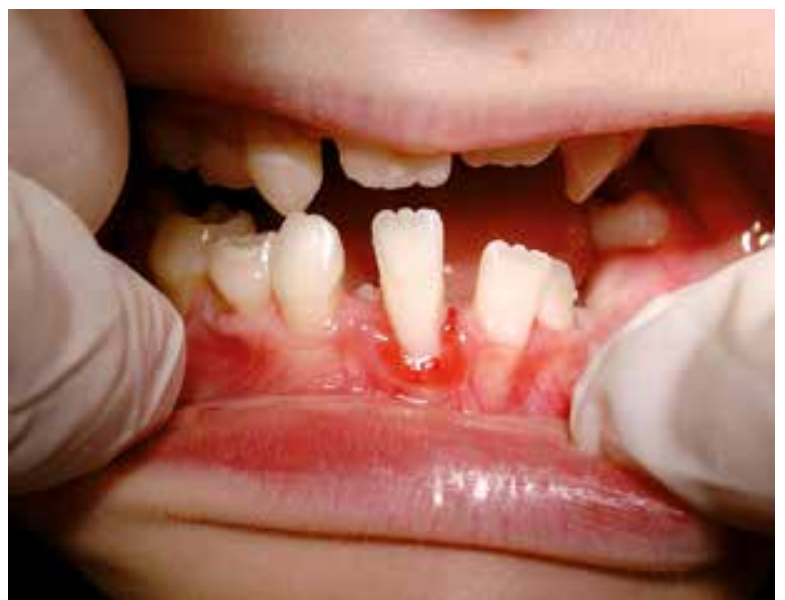

Figure 1. Periodontal inflammation around the permanent tooth an extremely low level of vitamin $\mathrm{E}$, and a very high level of hydroperoxidase $[44,45]$.

\section{Case report}

The 9-year-old patient, permanently under hospital care, came to the Department of Paediatric Dentistry due to the periodontitis and dental caries of the primary teeth. The patient's past medical history showed frequent purulent upper respiratory tract infections and purulent appendicitis. The dental caries was found on primary teeth: $55,54,65,75,84,85$, and periodontitis around the permanent tooth 41 (redness, spontaneous bleeding, gum recession, increased mobility) and around primary teeth $54,53,63,83,84$ (gum recession and dental deposits). Teeth 52, 62, 64, 73, 74 were missing (according to the dental history, they were lost due to excessive mobility and advanced periodontitis) (Figures 1, 2). Apart from oral symptoms, erythema, hyperkeratosis, and hyperhidrosis of the hands and feet, and also ear lobe hypoplasia were noted.

The therapy of periodontal disease, based on the bacterial plaque control did not bring expected results. The microbial analyses of the periodontal pocket of tooth 41 showed presence of Aggregatibacter actinomycetemcomitans ( $\mathrm{Aa}$ ). According to the antibiogram, antibiotic therapy with amoxicillin/clavulanic acid was ordered at the recommended doses for 2 weeks. Before the implementation of the antibiotic therapy, a peripheral blood flow cytometry was performed, and after 4 months it was repeated to assess the effectiveness of the treatment and the dynamics of change.

The results of peripheral blood flow cytometry are presented in Table 1. The first analysis of the peripheral blood leukocyte population showed a slightly lowered percentage of lymphocytes, but absolute values were within the normal range. In the immunophenotypic im-

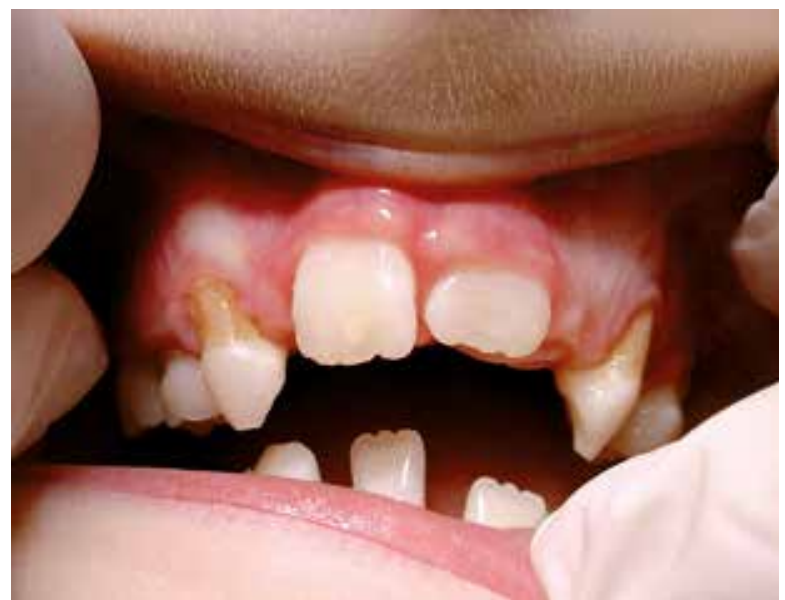

Figure 2. Periodontal destruction around the primary teeth 
Table 1. The results of peripheral blood flow cytometry

\begin{tabular}{lccccc}
\hline Parameter & $\mathbf{1}^{\text {st }}$ examination & $\mathbf{2}^{\text {nd }}$ examination & Parameter & $\mathbf{1}^{\text {st }}$ examination & $2^{\text {nd }}$ examination \\
\hline Lymphocytes & $33 \%$ & $38 \%$ & NK & $9 \%$ & $11 \%$ \\
\hline Neutrophils & $58 \%$ & $54 \%$ & CD11a-limf & $18 \%$ & $38 \%$ \\
\hline Basophils & $1 \%$ & $1 \%$ & CD11a-gran & $81 \%$ & $100 \%$ \\
\hline Monocytes & $4 \%$ & $5 \%$ & CD11b-limf & $11 \%$ & $10 \%$ \\
\hline CD45 & $94 \%$ & $98 \%$ & CD11b-gran & $100 \%$ & $100 \%$ \\
\hline CD19 & $19 \%$ & $17 \%$ & CD11c-limf & $10 \%$ & $5 \%$ \\
\hline CD3 & $67 \%$ & $68 \%$ & CD11c-gran & $100 \%$ & $100 \%$ \\
\hline CD4 & $51 \%$ & $52 \%$ & CD18-limf & $85 \%$ & $94 \%$ \\
\hline CD8 & $13 \%$ & $15 \%$ & CD18-gran & $100 \%$ & $100 \%$ \\
\hline CD4/CD8 & 3.80 & 3.47 & & &
\end{tabular}

age, there was a notable reduction in the percentage and number of T CD8 + lymphocytes. The CD4: CD8 ratio was increased. The percentage and number of B-lymphocytes approached the lower limit of the norm. In contrast, the adhesion molecules expression of the CD11a, CD11b, CD11c, and CD18 leukocytes was normal. After 4 months in the immunophenotypic study of peripheral blood leukocytes, the percentage and the absolute number of lymphocytes were within the age range. In the distribution of basic subpopulations, the reduction in the percentage of the absolute number of T-CD 8 + cells and an increase in the CD4 + cell value was notable. The CD4 : CD8 ratio was thus increased. The percentage and number of B lymphocytes and NK cells were normal. Expression of leukocyte adhesion molecules was normal.

\section{Discussion}

PLS diagnosis poses many problems. Although it is mainly established basing on oral pathognomonic lesions as well as excessive keratosis of the palms and soles, but other clinical signs may be similar to those present in acrodynia (Pinek's disease, Swift's disease), hypophosphatasia, histiocytosis X, cyclic and congenital neutropenia, Chediaki-Higashi syndrome, Thost-Uny disease and Meleda disease (keratosis palmoplantaris transgrediens). Therefore, an attempt to find a differential test is justified.

In the described study, flow cytometry was used to qualitatively and quantitatively assess the physical and biological properties of the cells. This method, thanks to immunomorphic and functional assessment of immune system cells, has been used in the diagnosis of congenital and acquired immunodeficiency syndromes, multidrug resistance and cancer. It is also used in the diagnosis of proliferative, neoplastic and deficiency lesions in the oral cavity. Moreover, it enables functional examination of cells and the mechanisms responsible for the initiation and progression of periodontitis, among others the study of the expression of the CCR6 protein on CD4 lympho- cytes isolated from inflamed tissues of the periodontium, responsible for chemotaxis. It can also serve to differentiate particular types of periodontitis using the quantitative diagnosis of $T$ (CD3) and B (CD19) lymphocytes and subpopulations of T helper cells (CD4) and suppressor (CD8) lymphocytes in chronic and aggressive periodontitis [46]. In patients with chronic periodontitis, CD19 levels were higher than CD3 levels, although the result was not statistically significant. In contrast, in patients with aggressive periodontitis, CD4 levels were higher than CD8 levels [47, 48]. Comparing the CD4 : CD8 ratio did not show a significant difference in patients with gingivitis and advanced chronic periodontitis [49]. However, when differentiating aggressive and chronic periodontitis, the difference was statistically significant [50]. In the described case, this ratio was also disturbed, as in aggressive periodontitis, still, clinical signs and no response to treatment with a targeted antibiotic suggest the PLS.

Treatment of PLS patients is symptomatic and often ineffective. Early management of the periodontal destruction in PLS patients includes eliminating the reservoir of causative organisms, using conventional periodontal treatment, oral hygiene instructions, antiseptic mouth rinses, and systemic antibiotic therapy. During the growth period, intensive orthodontic and prosthetic therapy is necessary, and periodontal care sometimes allows to maintain a part of the patient's dentition. Failure to respond to antibiotic therapy is significant in the treatment of PLS. Therapy with a mixture of amoxicillin and metronidazole applied in the initial treatment throughout 2 weeks followed by a long-term tetracycline treatment brings no improvement [27]. Similarly, treatment with retinoids is not very effective. Some authors suggest that a 3-year treatment with a systematic plaque control at three-monthly intervals brought good results $[9,11,24]$. Sometimes extraction of primary teeth with advanced periodontitis is recommended [11, 24], still before permanent teeth eruption. Also, Ullbro et al. [11] and Haneke [9] suggest extraction of all primary teeth under antibiotic 
prophylaxis at least 6 months before permanent teeth eruption. This prophylaxis includes amoxicillin/clavulanic acid of 20-40 mg/kg/day in divided doses every $8 \mathrm{~h}$, minimum 2 weeks before extraction. Some authors recommended extracting all primary and permanent teeth and fabricating the removable dental prostheses. Also, some authors described using of titanium implants for these patients [34, 38, 51].

In the treatment of skin lesions like keratoderma, anti-inflammatory emollients, keratolytic drugs, salicylic acid derivatives, and steroids are most commonly used. It is recommended to treat all family members, including animals (especially dogs) if they are pathogen carriers. It needs to be highlighted that salicylic acid topical may cause skin reaction, such as peeling, burning or reddening, which may occur just a few minutes after applying or after a longer time. Serious allergic reactions or severe skin irritations are observed rarely.

\section{Conclusions}

Apart from genetic testing, the blood tests in a flow cytometer should be considered as another method facilitating the diagnosis of periodontitis in genetic diseases and differential diagnosis between individual disease entities.

\section{Acknowledgments}

Patient's parents have given consent to the publication of photographs used in this publication.

\section{Conflict of interest}

The authors declare no conflict of interest.

\section{References}

1. Papillon MM, Lefèvre P. Deux cas de kératodermie palmaire et plantaire symmétrique (maladie de Meléda) chez le frère et la soeur. Coexistence dan les deux cas d'altérations dentaires graves. Bull Soc Fr Derm Syph 1924; 31: 82-4.

2. Pilger U, Hennies HC, Truschnegg A, Aberer E. Late-onset Papillon-Lefèvre syndrome without alteration of the cathepsin C gene. J Am Acad Dermatol 2003; 49: 240-3.

3. Toomes C, James J, Wood AJ, et al. Loss-of-function mutations in the cathepsin C gene result in periodontal disease and palmoplantar keratosis. Nat Genet 1999; 23: 421-4.

4. Hart TC, Hart PS, Bowden DW, et al. Mutations of the cathepsin C gene are responsible for Papillon-Lefevre syndrome. J Med Genet 1999; 36: 881-7.

5. Gorlin RJ, Cohen MM Jr, Hennekam RCM. Syndromes of the Head and Neck. Oxford University Press 2001; 1101-3.

6. Kinane D, Peterson M, Stathopoulou P. Environmental and other modifying factors of the periodontal diseases. Periodontol 2000 2006; 40: 107-19.

7. Griffiths WAD, Judge MR, Leigh IM. Disorders of keratinization. In: Rook, Walkinson. Ebling textbook of dermatology.
Vol. 2. $6^{\text {th }}$ ed. Champion RH, Burton JL, Burns DA, Breathnach SM (eds). Malden (MA): Blackwell Science 1998; 1483-588.

8. Gorlin RJ, Sedano H, Anderson VE. The syndrome of palmarplantar hyperkeratosis and premature periodontal destruction of the teeth: a clinical and genetic analysis of the Papillon-Lefevre syndrome. J Pediatr 1964; 65: 895-908.

9. Haneke E. The Papillon-Lefèvre syndrome: keratosis palmoplantaris with periodontopathy; report of a case and review of the cases in the literature. Hum Genet 1979; 51: 1-35.

10. Dalgic B, Bukulmez A, Sari S. Eponym-Papillon-Lefevre syndrome. Eur J Pediatr 2011; 170: 689-91.

11. Ullbro C, Crossner CG, Nederfors T, et al. Dermatologic and oral findings in a cohort of 47 patients with Papillon-Lefevre syndrome. J Am Acad Dermatol 2003; 48: 345-51.

12. Morgan RD, Hannon E, Lakhoo K. Renal abscess in PapillionLefèvre syndrome. Pediatr Surg Int 2011; 12: 1381-3.

13. Oguzkurt P, Tanyel FC, Buyukpamukcu N, et al. Increased risk of pyogenic liver abscess in children with Papillon-Lefevre syndrome. J Pediatr Surg 1996; 31: 955-6.

14. Almuneef M, Al Khenaizan S, Al Ajaji S, et al. Pyogenic liver abscess and Papillon-Lefevre syndrome: not a rare association. Pediatrics 2003; 111: e85-8.

15. Corson EF. Keratosi palmaris et plantaris with dental alteration. Arch Dermatol Syph 1939; 40: 639.

16. Van Dyke TE, Taubman MA, Ebersole JL, et al. The PapillonLefevre syndrome: neutrophil dysfunction in the severe periodontal disease. Clin Immunol Immunopathol 1984; 31: 419-29.

17. Zugor V, Schott GE, Labanaris AP. Xanthogranulomatous pyelonephritis in childhood: a critical analysis of 10 cases and the literature. Urology 2007; 70: 157-60.

18. Al-Benna S, Hasler R, Stricker I, et al. Papillon-Lefevre syndrome an squamous cell carcinoma: a case report. Cases J 2009; 28: 67-70.

19. Nakajima K, Nakano H, Takiyoshi N, et al. Papillon-Lefevre syndrome and malignant melanoma. A high incidence of melanoma development in Japanese palmoplantar keratoderma patients. Dermatology 2008; 217: 58-62.

20. Amer M, Mostafa FF, Tosson Z, et al. Papillon-Lefevre syndrome associated with albinism. Clinical and immunological study. J Eur Acad Dermatol Venereol 1996; 6: 246-51.

21. Henderson H, Curtis M, Seymour R, et al. Periodontal Medicine and Systems Biology. Wiley-Blackwell Oxford 2009; 81-2.

22. Noack B, Gorgenss H, Schacher B, et al. Functional cathep$\sin C$ mutations cause different Papillon-Lefevre syndrome phenotypes. J Clin Periodonol 2008; 35: 311-6.

23. Meyle J, Gonzales J. Influences of systemic diseases on periodontitis in children and adolescents. Periodontology 2000 2001; 26: 92-112.

24. Lenartowicz-Lotko A, Radwan-Oczko M. Zespół PapillonaLefevre - objawy kliniczne, diagnostyka i kompleksowe leczenie choroby przyzębia z opisem przypadku. Dental Forum 2011; 39: 89-92.

25. Markunina M, Piotrowski P. Zespół Papillona-Lefevre’a u 4-letniego chłopca. Pozn Stom 2002; 29: 173-8.

26. Markunina M, Wdowiak M, Orzeszko-Spaczyńska A. Zespół Papillona-Lefevre'a u 3,5-letniego chłopca. Prz Stom Wieku Rozw 2001; 3: 60-2.

27. Lundgren T, Renvert S. Periodontal treatment of patients with Papillon-Lefevre syndrome: a 3-year follow up. J Clin Periodontol 2004; 31: 933-8. 
28. Vrahopoulos TP, Barber P, Diakoni H, el al. Ultrastructure of the periodontal lesion in a case of Papillon-Lefevre syndrome(PLS). J Clin Periodontol 1988; 15: 17-26.

29. Kleinfelder JW, Topoll HH, Preus HR, el al. Microbiological and immunoeitological findings in a patient with PapillonLefevre syndrome. J Clin Periodontol 1996; 23: 1032-8.

30. Djawari D. Deficient phagocytic function in Papillon-Lefèvre syndrome. Dermatologica 1978; 156: 189-92.

31. Newman MG, Angel L, Karge H. Bacterial studies of the Papillon-Lefevre syndrome. J Dent Res 1977; 56: 545-7.

32. Ratetschak-Pluss EM, Schroeder HE. History of periodontitis in a child with Papillon-Lefèvre syndrome. A case report. J Periodontol 1984; 55: 35-46.

33. Page RC, Schroeder HE. Periodontitis in Man and Other Animals. Karger 1982.

34. Firatli E, Gurel N, Efeoglu A. Papillon-Lefèvre syndrome. Analysis of peripheral blond lymphocyte subjects. J Clin Periodontol 1996; 23: 823-5.

35. Ryu OH, Choi SJ, Firatli E, et al. Proteolysis of macrophages inflammatory protein-1 alpha isoforms LD78beta and LD78alpa by neutrphilderivad serine-proteases. J Biol Chem 2005; 29: 17415-21.

36. Schroeder HE, Seger RA, Keller HU, el al. Behavior of neutrophilic garnulocytes in a case of Papillon-Lefevre syndrome. Clin Periodontol 1983; 10: 618-35.

37. Sørensen OE, Clemmensen SN, Dahl SL, et al. PapillonLefèvre syndrome patient reveals species-dependent requirements for neutrophil defenses. J Clin Invest 2014; 124: 4539-48.

38. Liu R, Cao C, Meng H, el al. Leucocyte funtions in 2 cases of Papillon-Lefevre syndrome. J Clin Periodontol 2000; 27: 69-73.

39. Sadik ChD, Noack B, Schacher B, el al. Cytokine production by leukocytes of Papillon-Lefevre syndrome patients in whole blood cultures. Clin Oral Invest 2012; 16: 591-7.

40. Hodge P, Michalowicz B. Genetic predisposition to periodontitis in children and young adults. Periodontology 2000 2001; 26: 113-34.

41. Hewitt C, Wu CL, Hattab FN, et al. Coinheritance of two rare genodermatoses (Papillon-Lefèvre syndrome and oculocutaneous albinism type 1) in two families: a genetic study. Br J Dermatol 2004; 151: 1261-5.

42. Cury VF, Gomez RS, Costa JE, et al. A homozygous cathepsin C mutation associated with Haim-Munk syndrome. Br J Dermatol 2005; 152: 353-6.

43. Tonetti MS, Mombelli A. Early-onset periodontitis. Ann Periodontol 1999; 4: 39-53.

44. Battino M, Ferreiro M, Quiles J, et al. Alterations in the oxidation products, antioxidant markers, antioxidant capacity and lipid patterns in plasma of patients affected by PapillonLefevre syndrome. Free Radic Res 2003; 37: 603-9.

45. Battino M, Ferreiro M, Bompadre S, el al. Elevated Hydroperoxide levels and antioxidant patterns in Papillon-Lefevre syndrome. J Periodontol 2001; 72: 1760-6.

46. Burchardt D, Imachowska L, Derwich K, et al. Cytometria przepływowa - możliwości zastosowania w diagnostyce klinicznej zmian w obrębie jamy ustnej. Nowiny Lekarskie 2008; 77: 324-9.

47. Thomasini RL, Bonon SH, Durante P, el al. Correlation of cytomegalovirus and human herpesvirus 7 with CD3+ and CD3+ CD4+ cells in chronic periodontitis patients. J Periodontal Res 2012; 47: 114-20.
48. Loos BG, Roos MT, Schellekens PT, et al. Lymphocyte numbers and function in relation to periodontitis and smoking. J Periodontol 2004; 75: 557-64.

49. Petit MD, Hovenkamp E, Hamann D, et al. Phenotypical and functional analysis of T cells in periodontitis. J Periodontal Res 2001; 36: 214-20.

50. Papantonopoulos G, Takahashi K, Bountis T, et al. Aggressive periodontitis defined by recursive partitioning analysis of immunologic factors. J Periodontol 2013; 84: 974-84.

51. Adbulwassie H, Dhanrajani PJ, Jiffry A. Papillon-Lefevre syndrome. Reapprraisal of etiology, clinical features and treatment. II. Oral rehabilitation using osseointegrated implants. Indian J Dent Res 1996; 7: 63-70. 